\title{
Barreiras à prática de atividades físicas no lazer em usuários de transporte público de Campo Grande/MS
}

\section{Barriers to the practice of leisure-time physical activities among public transport users in Campo Grande/MS}

\author{
Barreras a la práctica de actividades físicas en el tiempo libre entre los usuarios del \\ transporte público en Campo Grande / MS
}

Valéria Rieger Vieira ${ }^{\mathrm{a}}(\mathrm{D})$, Junior Vagner Pereira da Silva ${ }^{\mathrm{a}^{*}}$

Palavras-chave: Atividades de lazer; Acessibilidade a Programas; Desenvolvimento humano; Adultos.

\section{Keywords:}

Leisure activities; Health Services Accessibility; Human development; Adults.

\section{Keywords:}

Actividades recreativas; Accesibilidad a los Servicios de Salud; Desarrollo humano; Adultos.

\begin{abstract}
RESUMO
Objetivou-se detectar as barreiras às atividades físicas no lazer (AFL) e correlacioná-las com o sexo e a região de residência. Participaram 389 adultos usuários de transporte público, dos sexos masculino e feminino. O sexo feminino associou-se estatisticamente com ambiente insuficientemente seguro, tarefas domésticas, compromissos familiares, falta de companhia, falta de recursos financeiros, falta de conhecimento/orientação, falta de energia/cansaço físico, falta de habilidades físicas, dores leves/mal-estar, falta de interesse e preocupação com a aparência. A região de moradia associou-se estatisticamente com a falta de equipamentos. Conclui-se que o lazer dos participantes é influenciado pelo contexto, envolvendo características biopsicossociais, experiências, políticas públicas e papéis sociais.
\end{abstract}

\begin{abstract}
The objective was to detect barriers to LPA and correlate them with gender and region of residence. A total of 389 adult users of public transport, male and female, participated. Females were statistically associated with an insufficiently safe environment, household chores, family commitments, lack of companionship, lack of financial resources, lack of knowledge/ orientation, lack of energy/physical fatigue, lack of physical skills and mild pain. being, lack of interest and preoccupation with appearance. The region of residence was statistically associated with the lack of equipment. In conclusion, the participants' leisure is influenced by the context, involving biopsychosocial characteristics, experiences, public policies and social roles.
\end{abstract}

\section{RESUMEN}

El objetivo era detectar las barreras a la LPA y correlacionarlas con el género y la región de residencia. Participaron un total de 389 usuarios adultos del transporte público, hombres y mujeres. Las mujeres se asociaron estadísticamente con un entorno insuficientemente seguro, tareas domésticas, compromisos familiares, falta de compañía, falta de recursos económicos, falta de conocimiento/orientación, falta de energía/fatiga física, falta de habilidades físicas y dolor leve. interés y preocupación por la apariencia. La región de residencia se asoció estadísticamente con la falta de equipamiento. En conclusión, el ocio de los participantes está influenciado por el contexto, involucrando características biopsicosociales, vivencias, políticas públicas y roles sociales. a Universidade Federal de Mato Grosso do Sul, Faculdade de Medicina, Programa de Pós-graduação em Saúde e Desenvolvimento na
Região Centro-Oeste, Campo Grande, MS, Brasil.

\footnotetext{
*Autor correspondente:

Junior Vagner Pereira da Silva

E-mail: jr_lazer@yahoo.com.br
} 


\section{INTRODUÇÃO}

A atividade física é compreendida como qualquer movimento corporal que produz gastos energéticos (Caspersen et al., 1985) no trabalho, deslocamento, afazeres domésticos e lazer (Florindo et al., 2009). Por seu turno, a atividade física no lazer (AFL) tem sido concebida como gastos energéticos decorrentes da ação motora no tempo disponível (Salles-Costa et al., 2003).

Embora amplamente referendadas pela literatura, com aplicação frequente em análises sobre o fator de proteção da AFL às doenças crônicas não transmissíveis (DCNT) (Moore et al., 2016) e o potencial para redução medicamentosa e de hospitalizações decorrente das DCNT (Bielemann et al., 2010), tais definições assumem estrutura anatomofisiológica como ponto de partida e de chegada, em que o ato mecânico da estrutura muscular, ao agir, exige maior consumo energético, se associando positivamente à melhor aptidão física. De modo reducionista e funcionalista, se justifica que a ocupação com a AFL, por si, quando realizada na intensidade e duração preconizadas, resultará em prevenção às doenças e promoção à saúde.

Contrariando essa abordagem, Piggin (2020, p. 5) assume nova interpretação. Entendendo-a como ação complexa e holística, em que a experiência humana é composta por aspectos fisiológicos, psicológicos, emocionais, afetivos, sociais, políticos e culturais, o autor adota como ponto de partida as pessoas, pois "A atividade física envolve pessoas se movendo, agindo e atuando em espaços e contextos culturalmente específicos e influenciados por uma gama única de interesses, emoções, ideias, instruções e relacionamentos".

Aplicando esse conceito às experiências vivenciadas em um tempo disponível, em que se requer uma atitude do sujeito, o lazer figura como elemento da cultura historicamente situado, que dispõe de espaços culturais específicos para esse fim, de modo a proporcionar que a população se ocupe com atividades físicas vinculadas aos diferentes interesses culturais (físico-esportivos, intelectuais, artísticos, manuais, sociais e turísticos) e se desenvolva fisiológica, emocional, afetiva, social e politicamente. Portanto, as experiências de lazer não estão vinculadas apenas a elementos comportamentais (que exigiria orientações e estímulo, como por muito tempo foi defendido pela vertente conservadora sobre a AFL), mas sim a um conjunto de fatores complexos que agem como barreiras.

Tal compreensão permite aproximar o conceito de atividade física elaborada por Piggin (2020) da teoria do Modelo Bioecológico do Desenvolvimento Humano (MBDH) de Bronfenbrenner (2011), assumindo que as experiências com as AFL decorrem do Processo-Pessoa-Contexto-Tempo (PPCT): Processo - experiências referentes à própria pessoa (self com terceiros e com as atividades); Pessoa - características biopsicossociais; Contexto - microssistema (ambiente imediato), mesossistema (inter-relação entre dois ou mais microssistemas), exossistema (ambiente distante que influencia mesmo sem envolver diretamente a pessoa) e macrossistema (cultura e políticas públicas); e Tempo - ordenamento dos eventos em sua sequência e contexto histórico (Bronfenbrenner, 2011).

Portanto, a atuação dessas barreiras ao lazer não implica problemas apenas biofisiológicos, como as DCNT (Moore et al., 2016), mas também psicológicos, emocionais, afetivos, sociais, políticos e culturais (Piggin, 2020), o que exige investigações que analisem a atuação de diferentes fatores sob experiências de AFL.

Neste cenário, problematiza-se um grupo específico da população (usuários de transporte coletivo) que dispõe de redução do seu tempo de AFL em virtude do percurso realizado entre sua residência e trabalho, comércio, universidade, entre outros, o que leva às seguintes indagações: quais são as barreiras à prática de AFL de usuários de transporte público em Campo Grande/ MS? Existe diferença na percepção das barreiras entre homens e mulheres? A percepção das barreiras pode estar associada à região de residência?

Mediante o exposto, objetivou-se investigar as barreiras que limitam/impedem os usuários de transporte público em Campo Grande/MS a ocupar o tempo disponível com AFL. Especificamente, analisa-se a associação de barreiras com o sexo e a região de residência.

\section{MÉTODOS}

Trata-se de pesquisa transversal com dados referentes a um momento específico (Sampieri et al., 2013), quantitativa, que se ocupa de dados, indicadores e tendências observáveis relacionadas ao ponto de vista social, aglomerados e conjuntos de informações demográficas (Minayo e Sanches, 1993), voltada a temas mais frequentes, gerais e universais sobre crenças e atitudes, com uso de questionários, análise estatística e apresentação em linguagem matemática em tabelas e quadros (Turato, 2005), e exploratória, que possibilita familiaridade com os problemas analisados a fim de compreendê-los e formular hipóteses (Sampieri et al., 2013).

A população foi de usuários de transporte público em Campo Grande/MS. Na delimitação da amostra, aplicaram-se parâmetros de coeficiente de confiança de $95 \%$ e erro amostral de $5 \%$, com exigência mínima de 383 sujeitos, selecionados aleatoriamente. Os critérios de inclusão foram ter idade de 18 a 59 anos, ser residente em Campo Grande/MS e estar em terminal de transporte municipal no momento da coleta. Já os critérios de exclusão foram ser pessoa com deficiência física ou doença que impossibilitasse a prática de AFL.

A pesquisa foi realizada entre agosto e outubro de 2018, e a amostra final contou com 389 usuários, com estratificação nos terminais existentes nas regiões do município, exceto a do Segredo, por não dispor dessa infraestrutura. $\mathrm{O}$ controle do número de entrevistados 
ocorreu tão somente em relação ao local de coleta (terminais), não se aplicando à região de residência (Quadro 1).

A técnica de investigação foi a entrevista estruturada, realizada individualmente, com abordagem aleatória e não sistematizada dos usuários no próprio terminal de transporte público durante a espera pelo transbordo. Para a abordagem, apresentação da pesquisa, seus respectivos objetivos, participação voluntária e anônima, assinatura do Termo de Consentimento Livre e Esclarecido (TCLE) e aplicação do instrumento, calculou-se um tempo médio por entrevista de 15 minutos.

A entrevista foi conduzida com o uso de formulário adaptado de Martins e Petroski (2000), o qual avalia o percentual de casos em que cada fator atua como barreira - "quase sempre" ou "sempre" (barreiras percebidas). Barreiras identificadas como "às vezes", "raramente" ou "nunca" foram descartadas. Na categorização dos dados, consideraram-se as dimensões sugeridas por Boscatto et al. (2011), que classificam as barreiras como ambientais (clima inadequado, falta de espaço disponível, ambiente insuficientemente seguro e condições inadequadas no local onde se vive), sociais (jornada de trabalho extensa, compromissos familiares, tarefas domésticas, falta de incentivo da família e/ou amigos, falta de recursos financeiros, falta de conhecimentos/ orientação e falta de companhia), comportamentais (mau humor, medo de lesionar-se, falta de interesse em praticar e preocupação com a aparência, a exemplo do que vestir durante a prática) e físicas (falta de habilidade, limitações físicas, cansaço físico, dores leves e mal-estar).

$\mathrm{Na}$ análise estatística recorreram-se às frequências absoluta e relativa, teste qui-quadrado $\left(X^{2}\right)$ para associação entre as barreiras e o sexo, tabela de contingência $2 \times 2$, com correção de Yates, nível de significância de $5 \%$ ( $p=0,05$ e valor crítico de $\left.X^{2}=3,841\right)$ e distribuição qui-quadrado ( $X^{2}$ aderência), teste de homogeneidade, nível de significância de $5 \%(p=0,05$ e valor crítico de $X^{2}$ aderência $=12,592$ ) para associação entre região de residência e barreiras, com o uso do Epi Info 7.2.2.6.

Quadro 1. Terminais de transporte público conforme a região. Campo Grande/MS, 2018.

\begin{tabular}{|l|c|c|}
\hline \multicolumn{1}{|c|}{ REGIÃO } & TERMINAIS & AMOSTRA \\
\hline Anhanduizinho (R1) & Morenão & 55 \\
\hline Bandeira (R2) & Guaicurus & 55 \\
\hline Centro (R3) & General Osório & 56 \\
\hline Imbirussu (R4) & Júlio de Castilho & 56 \\
\hline \multirow{2}{*}{ Lagoa (R5) } & Aero Rancho & 56 \\
\cline { 2 - 3 } & Bandeirantes & 55 \\
\hline Prosa (R6) & Nova Bahia & 56 \\
\hline Segredo (R7) & - & - \\
\hline
\end{tabular}

Fonte: elaborado pelos autores.
O estudo foi aprovado pelo Comitê de Ética em Pesquisa com Seres Humanos sob parecer no 2.685.959, e usou-se a teoria do MBDH na interpretação dos efeitos dos aspectos do PPCT (Bronfenbrenner, 2011).

\section{RESULTADOS}

A amostra foi predominantemente feminina, de 18 a 23 anos, solteira, com ensino médio e residente no bairro Anhanduizinho, conforme a Tabela 1.

O ambiente insuficientemente seguro (criminalidade), a falta de equipamento disponível (domínio ambiental), a jornada de trabalho extensa e tarefas domésticas (domínio social), a falta de energia/

Tabela 1. Perfil dos usuários de transporte público. Campo Grande/MS, 2018 ( $n=389$ ).

\begin{tabular}{|c|c|c|}
\hline Variáveis & $f$ & $\%$ \\
\hline \multicolumn{3}{|l|}{ Sexo } \\
\hline Feminino & 242 & 62,21 \\
\hline Masculino & 147 & 37,79 \\
\hline \multicolumn{3}{|l|}{ Idade } \\
\hline De 18 a 23 & 113 & 29,05 \\
\hline De 24 a 29 & 71 & 18,25 \\
\hline De 30 a 35 & 42 & 10,80 \\
\hline De 36 a 41 & 53 & 13,62 \\
\hline De 42 a 47 & 46 & 11,83 \\
\hline De 48 a 53 & 52 & 13,37 \\
\hline De 54 a 59 & 12 & 3,08 \\
\hline \multicolumn{3}{|l|}{ Estado civil } \\
\hline Casado & 108 & 27,76 \\
\hline Divorciado & 14 & 3,60 \\
\hline Solteiro & 246 & 63,24 \\
\hline União estável & 20 & 5,14 \\
\hline Viúvo & 1 & 0,26 \\
\hline \multicolumn{3}{|l|}{ Escolaridade } \\
\hline Fundamental incompleto & 33 & 8,49 \\
\hline Fundamental completo & 34 & 8,74 \\
\hline Médio incompleto & 41 & 10,54 \\
\hline Médio completo & 173 & 44,47 \\
\hline Superior incompleto & 84 & 21,59 \\
\hline Superior completo & 24 & 6,17 \\
\hline \multicolumn{3}{|l|}{ Região residencial } \\
\hline Anhanduizinho (R1) & 100 & 25,71 \\
\hline Bandeira (R2) & 39 & 10,03 \\
\hline Centro (R3) & 10 & 2,57 \\
\hline Imbirussu (R4) & 64 & 16,45 \\
\hline Lagoa (R5) & 71 & 18,25 \\
\hline Prosa (R6) & 40 & 10,28 \\
\hline Segredo (R7) & 65 & 16,71 \\
\hline
\end{tabular}

Fonte: dados da pesquisa.

Legenda: $f=$ frequência absoluta; $\%$ = frequência relativa; $R 1$ = Região 1; R2 = Região 2; R3 = Região 3; R4 = Região 4; R5 = Região 5; R6 = Região 6; R7 = Região 7. 
cansaço físico, a falta de habilidades físicas (domínio físico), a falta de interesse em praticar e a preocupação com a aparência (domínio comportamental) foram as principais barreiras percebidas (Tabela 2).

O sexo feminino apresentou relação estatisticamente significativa com o ambiente insuficientemente seguro (domínio ambiental); com tarefas domésticas, compromissos familiares, falta de companhia, falta de recursos financeiros, falta de conhecimento/orientação sobre atividades físicas (domínio social); com falta de energia/cansaço físico, falta de habilidades físicas e dores leves ou mal-estar (domínio físico); e com falta de interesse em praticar e preocupação com a aparência durante a prática (domínio comportamental) (Tabela 3).

A região de residência apresentou relação estatisticamente significante com a falta de equipamentos no Anhanduizinho, Bandeira e Lagoa (Tabela 4).

\section{DISCUSSÃO}

Apesar de o clima figurar como principal barreira à AFL entre adolescentes e adultos brasileiros (Vieira e Silva, 2019), na presente investigação mostrou-se pouco influente, o que pode estar relacionado às características climáticas de Campo Grande/MS, que dispõe de chuvas pontuais, inverno seco e temperatura média de 23,4 으 durante o ano todo (Climate-data.org, 2019).

A predominância do ambiente inseguro como principal barreira no domínio ambiental é o oposto de dados secundários disponíveis que indicam Campo Grande/MS como uma das menos violentas do país
(SEJUSP, 2019). Tal percepção pode estar relacionada ao perfil da amostra e ao período disponível para a AFL, pois, sendo o comércio a principal atividade de trabalho no município (PLANURB, 2018), o que exige que o lazer ocorra antes (madrugada) ou depois do expediente comercial (anoitecer), esses horários podem despertar maior percepção de insegurança por causa da baixa claridade, menor circulação de veículos ou pessoas, patrulhamento e iluminação.

No domínio social, a predominância da jornada de trabalho extensa e tarefas domésticas corrobora a literatura, que evidencia a falta de tempo como principal barreira à prática de AFL (Jesus e Jesus, 2012; Pinto et al., 2017).

Os sujeitos da pesquisa encontram-se entre $18 \mathrm{e}$ 59 anos, logo, o trabalho e a casa/família correspondem aos papéis sociais tipificados como inerentes a adultos. Os papéis sociais condicionam comportamentos como esperados para a vida adulta, sobretudo as obrigações trabalhistas e familiares (Bronfenbrenner, 2011), o que contribui para a diminuição do tempo de lazer. Assim, a relação lazer e trabalho leva em conta fatores da estrutura social.

Aos usuários de transporte público, além da influência do trabalho, soma-se o tempo com deslocamento (casa/trabalho/casa), equivalente a 47 minutos por viagem, superior aos 22 minutos daqueles que utilizam transporte individual (SIMOB, 2018), o que pode ampliar ainda mais a atuação dessa barreira.

Tabela 2. Barreiras percebidas por usuários de transporte público. Campo Grande/MS, 2018 ( $n=389$ ).

\begin{tabular}{|c|c|c|c|}
\hline Domínios & Barreiras & f & $\%$ \\
\hline \multirow{4}{*}{ Ambientais } & Ambiente insuficientemente seguro (criminalidade) & 186 & 47,82 \\
\hline & Falta de equipamento disponível & 174 & 44,73 \\
\hline & Falta de espaço disponível para a prática & 122 & 31,36 \\
\hline & Clima inadequado (vento, frio, calor etc.) & 71 & 18,26 \\
\hline \multirow{7}{*}{ Sociais } & Jornada de trabalho extensa & 216 & 55,53 \\
\hline & Tarefas domésticas (para com sua casa) & 181 & 46,53 \\
\hline & Compromissos familiares (pais, cônjuge, filhos etc.) & 152 & 39,08 \\
\hline & Falta de companhia & 138 & 35,48 \\
\hline & Falta de recursos financeiros & 124 & 31,87 \\
\hline & Falta de conhecimento/orientação sobre exercício físico & 91 & 23,39 \\
\hline & Falta de incentivo da família/amigos & 81 & 20,82 \\
\hline \multirow{4}{*}{ Físicas } & Falta de energia (cansaço físico) & 129 & 33,16 \\
\hline & Falta de habilidades físicas & 72 & 18,51 \\
\hline & Dores leves ou mal-estar & 65 & 16,71 \\
\hline & Limitações físicas (por exemplo: muscular ou articular) & 63 & 16,20 \\
\hline \multirow{4}{*}{ Comportamentais } & Falta de interesse em praticar & 79 & 20,31 \\
\hline & Preocupação com a aparência durante a prática & 66 & 16,97 \\
\hline & Mau humor & 59 & 15,17 \\
\hline & Medo de lesionar-se & 55 & 14,14 \\
\hline
\end{tabular}

Fonte: dados da pesquisa.

Legenda: $f$ = frequência absoluta; \% = frequência relativa. 
Tabela 3. Barreiras percebidas por usuários de transporte público, estratificadas por sexo. Campo Grande/MS, $2018(n=389)$.

\begin{tabular}{|c|c|c|c|c|c|c|c|}
\hline \multirow{3}{*}{ Domínios } & \multirow{3}{*}{ Barreiras } & \multicolumn{6}{|c|}{ Sexo } \\
\hline & & \multicolumn{2}{|c|}{ Feminino } & \multicolumn{2}{|c|}{ Masculino } & \multirow{2}{*}{$\mathbf{X}^{2}$} & \multirow{2}{*}{$\mathbf{p}$} \\
\hline & & f & $\%$ & $\mathbf{f}$ & $\%$ & & \\
\hline \multirow{4}{*}{ Ambientais } & Ambiente insuficientemente seguro (criminalidade) & 134 & 55,37 & 52 & 35,37 & 13,866 & 0,0002 \\
\hline & Falta de equipamento disponível & 114 & 47,11 & 60 & 40,82 & 1,221 & 0,2692 \\
\hline & Falta de espaço disponível para a prática & 80 & 33,06 & 42 & 28,27 & 0,659 & 0,4168 \\
\hline & Clima inadequado (vento, frio, calor etc.) & 50 & 20,66 & 21 & 14,28 & 2,082 & 0,1490 \\
\hline \multirow{7}{*}{ Sociais } & Jornada de trabalho extensa & 133 & 54,96 & 83 & 56,46 & 0,034 & 0,8539 \\
\hline & Tarefas domésticas (para com sua casa) & 127 & 52,48 & 54 & 36,73 & 8,490 & 0,0036 \\
\hline & Compromissos familiares & 108 & 40,63 & 44 & 29,93 & 7,691 & 0,0056 \\
\hline & Falta de companhia & 97 & 40,08 & 41 & 27,89 & 5,417 & 0,0199 \\
\hline & Falta de recursos financeiros & 94 & 38,84 & 30 & 20,04 & 13,475 & 0,0002 \\
\hline & Falta de conhecimento/orientação sobre exercício físico & 68 & 28,10 & 23 & 15,65 & 7,234 & 0,0072 \\
\hline & Falta de incentivo da família/amigos & 54 & 22,31 & 27 & 18,37 & 0,641 & 0,4233 \\
\hline \multirow{4}{*}{ Físicas } & Falta de energia (cansaço físico) & 104 & 42,98 & 25 & 17,00 & 26,664 & $<0,0001$ \\
\hline & Falta de habilidades físicas & 61 & 25,21 & 11 & 7,48 & 17,889 & $<0,0001$ \\
\hline & Dores leves ou mal-estar & 50 & 20,66 & 15 & 10,20 & 6,454 & 0,0111 \\
\hline & Limitações físicas (por exemplo: muscular ou articular) & 46 & 19,01 & 17 & 11,56 & 3,205 & 0,0734 \\
\hline \multirow{4}{*}{ Comportamentais } & Falta de interesse em praticar & 58 & 23,97 & 21 & 14,28 & 4,715 & 0,0299 \\
\hline & Preocupação com a aparência durante a prática & 49 & 20,25 & 17 & 11,56 & 4,298 & 0,0382 \\
\hline & Mau humor & 38 & 15,70 & 21 & 14,28 & 0,054 & 0,8166 \\
\hline & Medo de lesionar-se & 35 & 14,46 & 20 & 13,60 & 0,007 & 0,9321 \\
\hline
\end{tabular}

Fonte: dados da pesquisa.

Legenda: $f$ = frequência absoluta; \% = frequência relativa; $x i$ = qui-quadrado; $p$ = grau de significância.

Na dimensão física, predominaram o cansaço físico e a falta de habilidades, barreiras também evidenciadas entre adultos brasileiros (Nogueira e Sousa, 2012). A falta de energia e o cansaço físico estão concatenados às barreiras sociais - jornada de trabalho extensa, tarefas domésticas, tempo gasto no deslocamento casa-trabalhocasa em transporte público -, comprovando a menor disposição da população às AFL.

O trabalho e a família são ambientes imediatos em que o adulto está diretamente inserido (microssistemas) e que se interagem, onde os acontecimentos em um afetam os demais (mesossistema), que, por sua vez, influenciam as atividades das pessoas nos outros ambientes. Os eventos do trabalho, da casa/família e a maneira como são percebidos condicionam comportamentos da pessoa em um terceiro microambiente, aqueles relacionados ao lazer. O cansaço pode decorrer da exaustão percebida nos demais ambientes da vida adulta, como o trabalho e o deslocamento em transportes coletivos.

A falta de habilidades físicas pode ser identificada pelos aspectos próprios à pessoa, sejam os denominados recursos bioecológicos - características que influenciam e estão relacionadas à própria experiência (Processo) ou a inexistência de experiência anterior com a AFL, o que resulta na autopercepção de falta de habilidades. Outra possível explicação à influência dessa barreira é a compreensão das práticas esportivas como sendo oportunidades de lazer vinculadas exclusivamente ao rendimento. Em tese, isso ocorre pelo fato de historicamente o esporte ter sido atrelado ao rendimento, em que movimentos estereotipados e tidos como certos figuraram como padrão único, desestimulando aqueles que não se encaixavam em tais padrões, como por vezes reproduzido no microssistema escolar, mais precisamente nas aulas de educação física, o que alerta sobre a importância desse componente curricular.

No domínio comportamental, a exemplo do evidenciado na literatura entre adultos (Jesus e Jesus, 2012; Nogueira e Sousa, 2012), houve o predomínio da falta de interesse em praticar a AFL, o que pode ter relação com questões da própria pessoa, como disposições desorganizadas passivas com a tendência para evitar a atividade. A preocupação com a aparência também foi frequente, o que decorre da insatisfação com a autoimagem diante de estereótipos de corpos que permeiam a sociedade.

Avalia-se que o acesso às AFL está condicionado a elementos da PPCT (Bronfenbrenner, 2011): a predominância da insegurança como barreira ambiental pelo ecossistema (política de infraestrutura municipal); a falta de tempo pela jornada de trabalho extensa e tarefas domésticas na dimensão social pela interação dos microssistemas trabalho e família (mesossistema) e valores culturais da sociedade capitalista atribuídos 


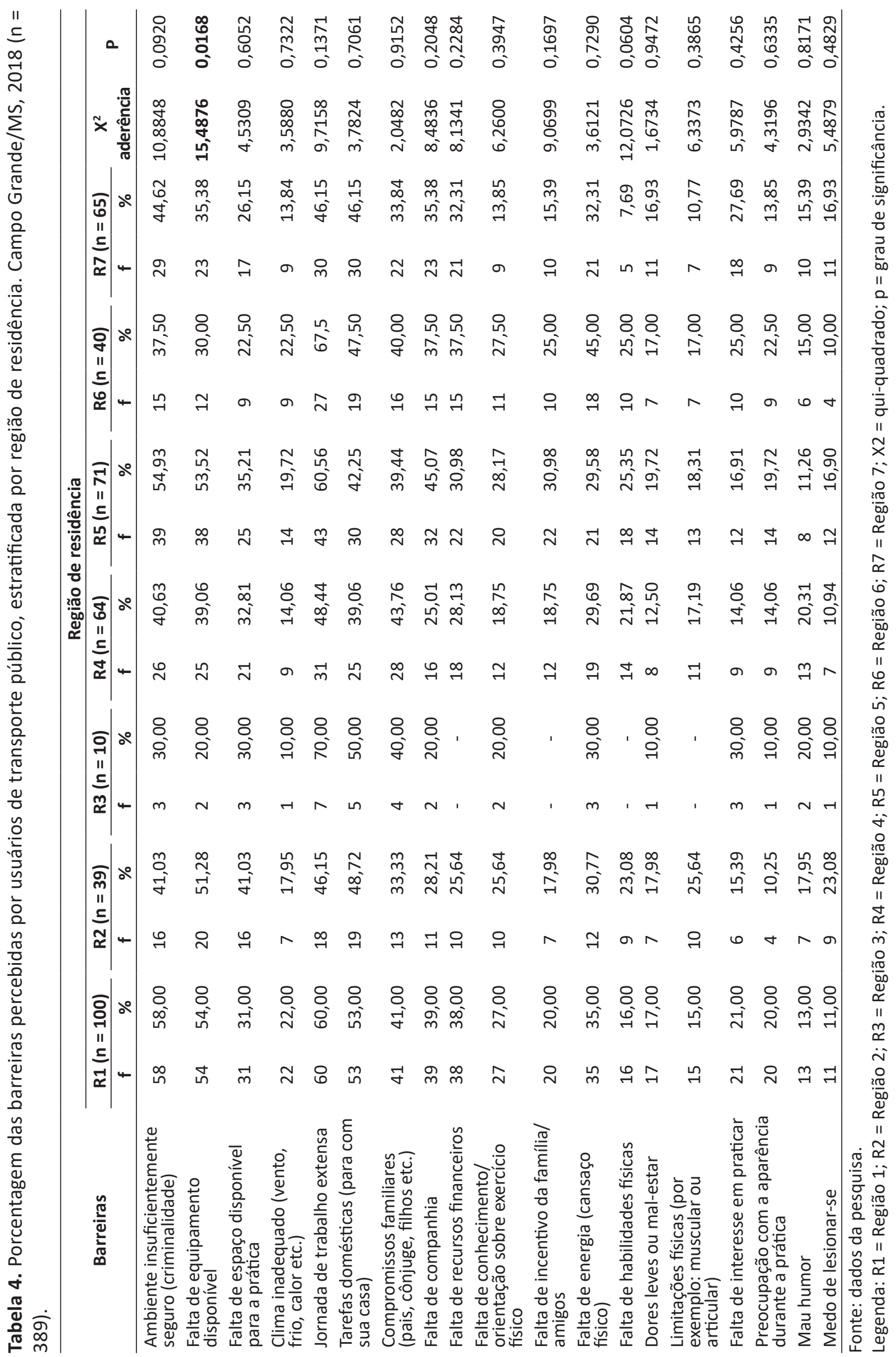


como responsabilidade da pessoa adulta (macrossistema) (Contexto); o cansaço físico, a falta de habilidades no domínio físico e as características biopsicossociais (Pessoa) influenciadas pelo contexto; a falta de interesse em praticar e a preocupação com aparência do domínio comportamental, relacionadas às experiências anteriores (Processo).

Ser mulher demonstrou associação estatisticamente significante com a maioria das barreiras analisadas: tarefas domésticas, compromissos familiares, falta de companhia, falta de recursos financeiros e falta de conhecimento/orientação sobre exercício físico (domínio social); cansaço físico, falta de habilidades físicas e dores leves ou mal-estar (domínio físico); ambiente insuficientemente seguro (domínio ambiental); e falta de interesse em praticar e preocupação com aparência (domínio comportamental).

Dados similares foram observados em outros estudos, com associação entre tarefas domésticas, compromissos familiares (Jesus e Jesus, 2012), falta de companhia, falta de recursos financeiros (Jesus e Jesus, 2012), cansaço físico (Silva et al., 2011), dores leves e/ou mal-estar (Nogueira e Sousa, 2012), falta de habilidades (Jesus e Jesus, 2012; Nogueira e Sousa, 2012) e falta de interesse em praticar (Jesus e Jesus, 2012; Nogueira e Sousa, 2012), figurando como barreiras à AFL das mulheres.

As questões de gênero apresentam variações nas experiências de lazer, pois os papéis sociais são diferenciados e abarcam também o comportamento de outros em relação à pessoa (Bronfenbrenner, 2011). A exemplo do que ocorre com as atribuições familiares e profissionais, nas AFL existem tipificações (padrões de interação) construídas historicamente por uma estrutura social (patriarcal, conservadora e machista), em que algumas experiências são tidas como apropriadas aos homens, e outras, às mulheres. Aqueles que desafiam agir de modo diferente são submetidos a mecanismos simbólicos de autoproteção, como o terapêutico, que, pautado em um "manual de patologias" e "detecção de indícios de anormalidades", empreende um conjunto de ações ostensivas de "cura/reeducação" ao dissidente com intuito de fazê-lo retornar aos padrões de interação estabelecidos, protegendo, assim, concepções de realidade vigentes (Duarte, 2004). Não raras são as associações de gênero com o tipo de vivências no tempo disponível, em que a sexualidade é questionada como recurso terapêutico àqueles que agem em sentido contrário aos "manuais de condutas" de esportes.

Essas tipificações ocorrem pela interconexão de contextos, dos mais próximos e imediatos, em que o indivíduo está em atividade em determinado momento da vida, como a família e a escola (microssistema), aos mais distantes ao sujeito, como a cultura, que engloba os demais ambientes (microssistema). Conforme Bronfenbrenner (2002), o processo inclui interconexões entre os ambientes e as influências exercidas, oriundas de meios amplos e, por vezes, advindas de ambientes em que a pessoa nem sequer está presente.

Sobre a influência de ações tidas como específicas/ predominantemente femininas entende-se que, embora as mulheres, diante de lutas históricas tenham conseguido maior inserção no mercado de trabalho nas últimas décadas, como analisa Sampaio (2011), as tarefas domésticas e os compromissos familiares ainda continuam sendo responsabilidades atribuídas a elas, o que resulta em menor tempo ao lazer.

Além de exercerem influência negativa sobre o tempo, as responsabilidades impostas socialmente às mulheres incorrem em efeitos físicos, como dores leves e/ou mal-estar. Considerando que os papéis sociais desiguais as colocam como responsáveis pelas tarefas domésticas/familiares e que, ainda assim, buscam responder a cobranças sociais do trabalho, a "jornada dupla" é estabelecida, o que explica o cansaço físico e as dores como barreiras no domínio físico (Pessoa), potencializada por valores culturais (macrossistema).

Somados aos fatores sociais, as dores leves e/ ou o mal-estar prevalente entre as mulheres ainda podem estar relacionados a fatores biológicos (Pessoa), dadas as particularidades do ciclo menstrual, que, por vezes, incidem em sintomas físicos de desconforto (Pedregal et al., 2017), o que, em determinados momentos, pode ser um fator limitador para a ocupação do tempo com experiências de lazer.

A associação entre gênero feminino, falta de habilidades físicas (domínio físico) e falta de conhecimento/ orientação sobre exercício físico (domínio social) pode ser explicada por valores culturais (macrossistema) reproduzidos desde a infância no âmbito familiar e escolar (microssistema) e interação entre eles (mesossistema), pois experiências da infância condicionam a vida adulta (Bronfenbrenner, 2002), como aquelas relacionadas às práticas corporais, que entendem que os "homens são fortes" e as "mulheres são frágeis" (Simões et al., 2004) e determinam que as atividades livres e vigorosas sejam feitas por meninos, enquanto as meninas são impedidas de praticá-las (Rangel e Darido, 2005), com repercussões nas aulas de educação física escolar (Adelman, 2003) e no lazer (Marcellino, 2002).

As experiências com as AFL no contexto escolar e familiar na infância, adolescência e vida adulta (Processo) também podem explicar a associação entre gênero feminino e falta de interesse em praticar atividade no domínio comportamental em razão do menor incentivo. Por seu turno, a preocupação com a aparência decorre de estereótipos culturais do corpo feminino ideal.

Portanto, em que pesem os parcos avanços em sentido contrário, historicamente o movimento de especificações de funções sociais ocorre desde a infância, sendo as meninas pouco estimuladas no contexto familiar a vivenciar jogos que exijam exploração, aventura, competitividade, agressividade ou maior vigor. $\mathrm{Na}$ escola ou políticas de lazer são mais estimuladas a 
aderirem experiências que envolvam precisão e estética quando comparadas as que exigem força e confronto. Tal direcionamento se estende ao longo do ciclo da vida e inibe a ocupação do tempo disponível com a AFL por perceberem destituídas de conhecimentos e habilidades para tal propósito.

No que concerne à associação entre região de moradia e barreiras às $A F L$, ela foi estatisticamente significante somente para a falta de equipamento disponível, com maior frequência entre moradores das regiões Anhanduizinho, Bandeira e Lagoa, localidades onde, conforme dados da Agência Municipal de Meio Ambiente e Planejamento Urbano (PLANURB, 2018), se encontra a população com menores rendimentos - Anhanduizinho (R\$1.811,94), Lagoa (R\$ 2.142,15) e Bandeira $(R \$ 2.687,73)$ - quando comparada à população que reside no Centro ( $\mathrm{R} \$ 5.884,37)$ e Prosa ( $\mathrm{R} \$ 4.725,34)$.

A geografia social brasileira seguiu o modelo parisiense implementado pelo Barão de Haussmann em 1830, por meio da expulsão de trabalhadores da região central para periferia, substituição de bairros mistos por aburguesados e criação de subúrbios não urbanizados aos operários (Hobsbawm, 2011), condição que até os dias de hoje está presente na centralidade elitizada da cidade, com imobiliários de alto valor, comércios elegantes, casas ricas, consumo cultural da moda e maior investimento público, criando territórios para a riqueza e, por conseguinte, estabelecendo o distante, o que fica à margem, na periferia, como territórios para a pobreza (Rolnik, 2007).

O local de residência, representado neste estudo pelas regiões da cidade, tem íntima relação com o poder econômico dos munícipes, pois a valoração territorial é estipulada pelo mercado imobiliário, o que explica que moradores de regiões de menor renda mensal tenham condições limitadas para destinar recursos financeiros à aquisição de equipamentos para a AFL.

Neste cenário, o sistema econômico e político, os valores culturais (macrossistema) e as políticas locais, como aquelas vinculadas ao plano de desenvolvimento urbano, como o plano diretor (exossistema), exercem importantes influências enquanto geradores de segregação, seja pela ausência de recursos financeiros para aquisição de equipamentos pessoais ou pela ausência da atuação do Estado enquanto responsável por políticas públicas direcionadas a equipamentos específicos de lazer.

Esses espaços são essenciais à $A F L$ não apenas para um estilo de vida fisicamente ativo, em que a frequência e a intensidade ideal para prevenção de doenças e promoção da saúde pautada na fisiologia sejam alcançadas, mas sobretudo por promover relações sociais (Gehl, 2013), coesão comunitária, expressão de vontades, conflitos coletivos e formação política (Borja, 2010), condições favoráveis à participação de programas de AFL em espaços públicos (Fernandes et al., 2017), o que fortalece a compreensão de que a AFL consiste em experiências humanas em que aspectos fisiológicos, psicológicos, emocionais, afetivos, sociais, políticos e culturais se manifestam e, para além da prevenção de doenças e proteção fisiológica, ajudam no desenvolvimento humano (Piggin, 2020).

Em que pese a influência de diversos fatores bioecológicos (PPCT) como barreiras ao lazer, é preciso considerar que a pessoa em desenvolvimento é uma entidade em crescimento e que progressivamente penetra e reestrutura o meio em que reside. A mais alta expressão do desenvolvimento é a crescente capacidade das pessoas remodelarem a realidade, o que ratifica a relevância de que perspectivem novos horizontes às experiências de AFL por meio da eliminação de barreiras existentes, como aquelas pautadas no lazer como objeto de educação (inserção da população em diversas possibilidades de AFL e também em experiências relacionadas a outros interesses culturais, artísticos, sociais, manuais, intelectuais e turísticos) e veículo de educação (oportunidades voltadas não somente para a prática funcionalista direcionada ao gasto energético, emagrecimento, culto ao corpo ideal, mas também ao desenvolvimento por meio de reflexões críticas e criativas em relação a oportunidades de lazer e valores nelas contidas), potencializadas pelas relações sociais em espaços de lazer.

\section{CONSIDERAÇÕES FINAIS}

Conclui-se que as principais barreiras à AFL entre os adultos usuários de transporte público em Campo Grande/MS são decorrentes: no domínio ambiental, do ambiente insuficientemente seguro (criminalidade) e da falta de equipamento disponível; no domínio social, da jornada de trabalho extensa e das tarefas domésticas (para com sua casa); no domínio físico, da falta de energia (cansaço físico); e no domínio comportamental, da falta de habilidades no domínio físico, da falta de interesse em praticar atividade e da preocupação com a aparência durante a prática.

As mulheres sofreram impacto da maioria das barreiras, o que reflete questões de gênero, como o estabelecimento de papéis sociais diferenciados a homens e mulheres desde a infância, que limitam experiências motoras femininas e lhes atribuem maiores funções domésticas, assim como a dupla jornada, com atribuições profissionais e domésticas familiares.

A falta de equipamento se mostrou estatisticamente relacionada ao local de moradia, o que indica que questões socioeconômicas figuram como variáveis que agem sobre a vivência do lazer, pois as três regiões com menor acesso a equipamentos também são as com menores taxas de renda da população.

\section{FINANCIAMENTO}

O presente trabalho contou com o apoio financeiro da Coordenação de Aperfeiçoamento de Pessoal de 
Nível Superior (CAPES), do tipo bolsa de mestrado, com o número do processo 171137.

\section{CONFLITOS DE INTERESSE}

Os autores declaram não haver conflitos de interesse.

\section{AGRADECIMENTOS}

Agradecimentos à Agência Municipal de Transporte e Trânsito (AGETRAN).

\section{REFERÊNCIAS}

Adelman M. Mulheres atletas: re-significações da corporalidade feminina. Rev Estud Fem (Online) 2003;11(2):445-65. http://dx.doi.org/10.1590/S0104-026X2003000200006.

Bielemann RM, Knuth AG, Hallal PC. Atividade física e redução de custos por doenças crônicas ao sistema único de saúde. Rev Bras Ativ Fís Saúde 2010;15(1):9-14. http://dx.doi. org/10.12820/rbafs.v.15n1p9-14.

Borja, J. La ciudade conquistada. Madrid: Alianza Editorial; 2010.

Boscatto EC, Duarte MDFS, Gomes MDA. Estágios de mudança de comportamento e barreiras para a atividade física em obesos mórbidos. Rev Bras Cineantropom Desempenho Hum 2011;13(5):329-34. http://dx.doi.org/10.5007/1980$0037.2011 v 13 n 5 p 329$.

Bronfenbrenner U. A ecologia do desenvolvimento humano: experimentos naturais e planejados. 2. ed. Porto Alegre: Artmed; 2002.

Bronfenbrenner U. Bioecologia do desenvolvimento humano: tornando os seres humanos mais humanos. Porto Alegre: Artmed; 2011.

Caspersen CJ, Powell KE, Christenson GM. Physical activity, exercise, and physical fitness: definitions and distinctions for health-related research. Public Health Rep 1985;100(2):126-31. PMid:3920711.

Climate-data.org. Dados climáticos para cidades mundiais [Internet]. 2019 [citado 2019 Mar 20]. Disponível em: https://pt.climate-data.org/america-do-sul/brasil/matogrosso-do-sul/campo-grande-3912/\#climate-graph

Duarte JF Jr. O que é realidade. São Paulo: Brasiliense; 2004.

Fernandes AP, Andrade ACS, Costa DAS, Dias MAS, Malta DC, Caiaffa WT. Programa Academias da Saúde e a promoção da atividade física na cidade: a experiência de Belo Horizonte, MG, Brasil. Cien Saude Colet. 2017;22(12):3903-14. http:// dx.doi.org/10.1590/1413-812320172212.25282017. PMid:29267708.

Florindo AA, Hallal PC, Moura EC, Malta DC. Prática de atividades físicas e fatores associados em adultos, Brasil, 2006. Rev Saúde Pública 2009;43(Supl 2):65-73. https:// doi.org/10.1590/S0034-89102009000900009.

Gehl J. Cidades para pessoas. São Paulo: Perspectiva; 2013.

Hobsbawm E. A era do capital. 15. ed. São Paulo: Paz e Terra; 2011.

Jesus GM, Jesus ÉFA. Nível de atividade física e barreiras percebidas para a prática de atividades físicas entre policiais militares. Rev Bras Ciênc Esporte 2012;34(2):433-48. http://dx.doi.org/10.1590/S0101-32892012000200013.

Marcellino NC. Estudos do lazer: uma introdução. São Paulo: Autores Associados; 2002.

Martins MO, Petroski EL. Measurement of perceived barriers to physical activities: Proposed research instrument. Rev Bras Cineantropom Desempenho Hum 2000;2(1):58-65.

Minayo MCS, Sanches O. Quantitativo-qualitativo: oposição ou complementaridade? Cad Saude Publica 1993;9(3):239-62. http://dx.doi.org/10.1590/S0102-311X1993000300002.

Moore SC, Lee I-M, Weiderpass E, Campbell PT, Sampson JN, Kitahara CM, et al. Association of Leisure-Time Physical Activity With Risk of 26 Types of Cancer in 1.44 Million Adults. JAMA Intern Med 2016;176(6):816-25. http://dx.doi.org/10.1001/jamainternmed.2016.1548. PMid:27183032.

Nogueira J, Sousa A. Barreiras percebidas e etapas de mudança de comportamento relacionadas à prática de atividade física em professores de escolas públicas. R Bras Ci Mov 2012;20(1):65-70. http://dx.doi.org/10.18511/rbcm. v20i1.2406.

Pedregal KAC, Medeiros KB, Silva JAC. Análise da força muscular e escolhas dietéticas de mulheres fisicamente ativas durante o ciclo menstrual. Rev Bras Nut Esp [Internet]. 2017 [citado 2019 Maio 5];11(64):507-15. Disponível em: http://www.rbne.com.br/index.php/rbne/article/ view/847

Piggin J. What is physical activity? A holistic definition for teachers, researchers and policy makers. Front Sports Act Living 2020;2:72. PMid:33345063.

Pinto A, Claumann G, Cordeiro P, Felden E, Pelegrini A. Barreiras percebidas para a prática de atividade física entre universitários de Educação Física. Rev Bras Ativ Fís Saúde 2017;22(1):66-75. http://dx.doi.org/10.12820/ rbafs.v.22n1p66-75.

PLANURB: Agência Municipal de Meio Ambiente e Planejamento Urbano. Dados demográficos de Campo Grande - MS [Internet]. Campo Grande (MS): PLANURB; 2018 [citado 2019 Fev 22]. Disponível em: http://www. campogrande.ms.gov.br/planurb/

Rangel ICA, Darido SC. Jogos e brincadeiras. In: Darido SC, Rangel ICA, organizadores. Educação Física na escola: implicações para a prática pedagógica. Rio de Janeiro: Guanabara Koogan; 2005. p. 155-175.

Rolnik R. A cidade e a lei: legislação, política urbana e territórios na cidade de São Paulo. São Paulo: FAPESP; 2007.

Salles-Costa R, Heilborn ML, Werneck GL, Faerstein E, Lopes CS. Gênero e prática de atividade física de lazer. Cad Saude Publica 2003;19(Suppl 2):S325-33. http://dx.doi.org/10.1590/S0102-311X2003000800014. PMid:15029352.

Sampaio TMV. O processo educativo do lazer: vivências de um grupo de mulheres. In: Sampaio TMV, Silva JVP. Lazer e cidadania: horizontes de uma construção coletiva. Brasília: UCB; 2011. p. 27-44.

Sampieri RH, Collado CF, Lucio PB. Metodologia de pesquisa. São Paulo: McGraw-Hill; 2013. 
SEJUSP: Secretaria de Estado de Justiça e Segurança Pública. Estatística da violência no Mato Grosso do Sul. [Internet]. 2019 [citado em 2019 Maio 15]. Disponível em: http:// estatistica.sigo.ms.gov.br/

Silva SG, Silva MC, Nahas MV, Viana SL. Fatores associados à inatividade física no lazer e principais barreiras na percepção de trabalhadores da indústria do Sul do Brasil. Cad Saude Publica 2011;27(2):249-59. http://dx.doi.org/10.1590/ S0102-311X2011000200006. PMid:21359461.

SIMOB: Sistema de Informações da Mobilidade Urbana. Relatório 2016 [Internet]. 2018 [citado em 2019 Jun 7]. Disponível em: http://files.antp.org.br/simob/simob-2016-v6.pdf
Simões AC, Conceição PFM, Nery MAC. Mulher, Esporte, Sexo e Hipocrisia. In: Simões AC, Knijnik JD, organizadores. O mundo psicossocial da mulher no esporte: comportamento, gênero, desempenho. São Paulo: Aleph; 2004. p. 61-86

Turato ER. Métodos qualitativos e quantitativos na área da saúde: definições, diferenças e seus objetos de pesquisa. Rev Saude Publica 2005;39(3):507-14. http:// dx.doi.org/10.1590/S0034-89102005000300025. PMid:15997330.

Vieira VR, Silva JVP. Barreiras à prática de atividades físicas no lazer de brasileiros: revisão sistematizada. Pensar Prát 2019;22:1-22. http://dx.doi.org/10.5216/rpp.v22.54448. 